\title{
Erratum to: Role of CD73 and extracellular adenosine in disease
}

\author{
Presented by Maria P. Abbracchio \\ Elliot Tapper • Moritz Schmelzle • Holger K. Eltzschig • \\ Simon C. Robson
}

Published online: 20 December 2011

(C) Springer Science+Business Media B.V. 2011

Erratum to: Purinergic Signalling (2011) 7:367-372

DOI 10.1007/s11302-011-9265-4

The original version of this article contained two errors.

The name of the first author of the first reviewed manuscript (NT5E mutations and arterial calcifications. N. Engl. J. Med. 2011 Feb 3;364(5):432-42. PMID: 21288095) was spelt incorrectly. The family name should have been "St. Hilaire" instead of "St. Hillaire".

Elliot Tapper, Moritz Schmelzle and Holger K. Eltzschig are coauthors and their corresponding affiliations are presented below.

\footnotetext{
The online version of the original article can be found at http://dx.doi. org/10.1007/s11302-011-9265-4.

E. Tapper $\cdot$ M. Schmelzle $\cdot$ S. C. Robson $(\bowtie)$

Beth Israel Deaconess Medical Center, Harvard University,

Boston, MA, USA

e-mail: srobson@bidmc.harvard.edu

H. K. Eltzschig

University of Colorado,

Aurora, CO, USA
} 